\title{
Optimization of Unmanned Ship's Parametric Subdivision based on Improved Multi-objective PSO
}

\author{
Shaojuan $\mathrm{Su}^{1,2,3 *}$, Jing Han ${ }^{1}$, Yeping Xiong ${ }^{3}$ \\ ( ${ }^{1}$ Naval Architecture and Ocean Engineering College,Dalian Maritime University, 116026, Dalian, Liaoning, China \\ ${ }^{2}$ Unmanned Ships Collaborative Innovation Institute, Dalian Maritime University, 116026, Dalian, Liaoning, China \\ ${ }^{3}$ Faculty of Engineering and Physical Sciences, University of Southampton, Boldrewood Innovation Campus, SO16 7QF \\ Southampton, UK) \\ ssjlpz@dlmu.edu.cn
}

\begin{abstract}
The optimization of ship's subdivision arrangement is an important part of ship general layout design. However, optimization to an unmanned ship's subdivision considering the complex multiobjective is less studied. In this paper, the multi-objective optimization of a V-type non-ballasted water unmanned ship compartment division is investigated based on parametric model. The principal rules of cabin division for unmanned ship are determined first. The shape and composition of the longitudinal inner shell layout and transverse inner shell structure are studied by three-dimensional parametric representation method. The cabin capacity, bending moment and water immersion factor are used as the objective functions to establish the mathematical model. The improved multi-objective particle swarm optimization (PSO) algorithm are used to optimize the unmanned ship's subdivision arrangement in which the generated front-end solutions are normalized and sorted by the distance from the origin to solved the multiple objectives. The grey relational degree calculation method is applied to verify the method. Finally, different subdivision scheme based on different objective is given. The findings provide useful guidelines for the design optimization of non-ballast water unmanned ships.
\end{abstract}

Keywords: unmanned ship; subdivision; parametric model; multi-objective particle swarm optimization; grey relational degree

\section{Introduction}

The realization of unmanned ships has become possible with the explosive development of artificial intelligence, big data, and internet of things. In 2016, the UK's Rolls-Royce and Tampere Technical University jointly developed key technologies for the first-generation unmanned ship systems (Jokioinen, 2016). In 2012, the "MUNIN" project (Maritime Unmanned Navigation through Intelligence in Networks) was jointly developed by eight research institutes such as Fraunhofer CML of Germany, MARINTEK of Norway and Chalmers University of Technology in Sweden. For the first time, the research on large unmanned ships was carried out with unmanned bulk carriers. The purpose was to verify the possibility of automatic navigation and unmanned ships, to study cutting-edge technologies and standards related to them, and to provide technical support for the revision of regulations. It is planned to complete the research on the possibility of unmanned ship development and autonomous navigation by 2034 (Burmeister et al., 2014, MUNIN, 2015, Rodseth, 2012, 2014,). In October 2016, the Norwegian Maritime Administration and the Norwegian Coastal Authority established the world's first autonomous ship test area. In the same 
month, the Norwegian Forum for Autonomous Ships (NFAS) was established, marking Norway's promotion of unmanned ship research to the national level (Rodseth,2017). The world's largest mining group developed a super-large automatic sailing (unmanned) bulk carrier for transporting various minerals, such as iron ore and coal (Seamen, 2017). The Japanese shipping industry is also vigorously developing unmanned ships and plans to build a large unmanned fleet in 2025 (Liu et al., 2017). On June 28, 2017, the establishment of the China Unmanned Cargo Ship Development Alliance Expert Committee and the Chief Designer Office marked the official establishment of China's unmanned ship R\&D technical system (Yi, 2017). Gao et al. (2017) reviewed the research status of unmanned ships, summarized the key issues of unmanned ship technology development, and forecasted the development prospects of unmanned ships. Su et al. (2018) proceeded from the ship design perspective to follow the ship design spiral and systematically analyzed various factors that should be considered in the design of unmanned ships. In the study, the ship's empty weight, hull design form, ship main engine selection, total layout design, and shipbuilding costs were discussed in detail.

The division and layout of ship compartments divide the internal space of the ship through various platforms and longitudinal and transverse bulkheads, thus improving the space utilization and functional requirements of the cabins. Boulougouris et al. (2004) proposed an internal compartmentation of Ro-Ro passenger ships (ROPAXs) optimization method. Maximization of ship's resistance against capsizes as well as maximizing the transport capacity were chosen as the objectives. Building cost reduction was also considered as the result of steel weight minimization. Santos et al. (2005) proposed a watertight subdivision optimization method for ferries. The mathematical model used in the study was established according to the target and design parameters of the hull watertight subdivision design, and the optimization calculation was carried out by multiobjective genetic algorithm. Ölcer et al. (2006) studied the multi-objective decision-making method for the layout of the ro-ro ship. The fuzzy multi-attribute decision-making technology was integrated into the multi-objective optimization method. Taking the damage stability, anti-sinking capability, and cargo volume as the optimization objectives, the genetic algorithm based on multi-objective optimization technology was used to solve the problem. Cabaj et al. (2007) optimized the hull subdivision based on the dip length and completed the conceptual design of three different ro-ro ships based on the SOLAS 2009 method. Cui and Turan (2009) proposed a multiple objective 'Hybrid Co-evolution based Particle Swarm Optimization' (HCPSO) methodology and utilized it to study the same case of (Ölcer, 2008). Chen et al. (2010) developed a ship's subdivision arrangement method for offshore sequential ballast and NSGA was utilized to perform the optimization. Koningh et al. (2011) developed a ship subdivision constraint management tool, defined the design elements of the ship subdivision in the tool, and supported the ship subdivision design work by modifying and adding to the tool. Gong (2013) developed a digital design for the FRP fishing boat cabin based on parametric design theory and database technology. The submarine layout of the hull, the calculation of the hydrostatic force, and the cabin capacity were realized. Pawlowski et al. (2014) discussed the impact of the damage stability of ro-ro ships on different subdivision arrangements. The analysis of 16 subdivision arrangements, unilateral and bilateral, above and below the car deck, and the concept of critical deck height, respectively, that when the liquid level is higher than this value, the hull will be quickly overturned. Jiang (2015) analyzed the inner shell structure of the cargo hull and proposed the parameterized expression of the inner shell structure. Jing et al. (2016) established the oil tank subdivision design based on the idea of risk minimization to minimize the 
amount of oil spill and to maximize the capacity and the force of the cargo hold on the hull girder at full load.

In 2017, Kongsberg, the Norwegian Yara Group, and Marin Teknikk jointly launched the world's first zero-emission unmanned ship project using electric propulsion described by China Maritime (2018). Their ship does not use crew members; it uses batteries for power and cancels the ballast tank. This paper was inspired by this ship design idea.

In this study, a 30000t oil tanker was converted to a non-ballasted water unmanned ship. A series of performance checks were then completed. The main scale was determined as shown in Table 1, and the parameterized modeling of the inside shell was established. Based on the cabin capacity, bending moment, and water immersion factor as objective functions, the mathematical model of subdivision arrangement was established, and the improved multi-objective particle swarm optimization (PSO) algorithm was used to optimize the subdivision.

\section{Cabin division principle}

The design ship discussed in the paper is V-type unmanned ship. By making the oblique angle of the bottom and increasing the height of the camber, the ship is changed from the ordinary U-shaped cross section to the V-shaped cross section as show in Figure 1. From the "unmanned" aspect, the ship deck cabins, living systems, life-saving equipment, fire-fighting equipment and other facilities that meet the crew's needs will be removed, the superstructure will be cancelled, and all kinds of domestic water and safety fire pipes inside the main hull will be removed which will save the internal space of the ship. At the same time, the various types of equipment that need to be added to the operation of the unmanned ship, such as intelligent network communication equipment, internal hull sensors and intelligent sensing equipment, alarm equipment, etc. should be considered and coordinated with the general layout design. From the aspect of "no ballast water", the ship does not need to install ballast water. In theory, the ship's ballast tank can be cancelled. However, based on structural strength and safety, the tanker continues to adopt double bottom and double shell structure.

At the same time, there is a main aspect that need to pay special attention. When sailing without load, serious trim by stern will occur because the floating state of ship cannot be adjusted by ballast water. For the problem, it can be solved by loading part of ballast water or moving forward through fuel tanks and domestic water tanks etc.

In this paper, the second method is adopted. The whole vessel becomes a mid-stern engine vessel, and the two compartments near the stern become cargo holds. Separated empty cabins are installed in the front and rear of the engine room to meet the safety requirements, and the trim by stern can be solved smoothly. However, the specific position of the engine room is taken as the design variable of the cabin optimization.

Figure 2 shows a preliminary schematic scheme. The entire main hull consists of six compartments in the longitudinal direction. Each compartment is divided into port and starboard two parts by the longitudinal bulkhead. The COT4 compartment indicates the approximate position of the engine room. Three cargo holds are arranged in front of the cabin, and two cargo holds are arranged at the rear. The initial side tank width is $2 \mathrm{~m}$. 


\section{Parametric expressions of the inner shell structure}

In the non-ballast water unmanned ship, the cross-sectional shape of the inner shell has a large change from that of the general tanker. The bottom of the ship produces an oblique angle and the height of the camber increases. According to the special section structure, the parameterized expression method (Perez, 2014; Jiang 2015) of the inner shell structure is proposed. In the longitudinal direction, the main body of the ship is fusiform, but the inner shell structure of the cargo holds is composed of flat plates. Therefore, the positions of bilge, the parallel middle body and the joint between the stem and the stern etc. will have chamfers and each chamfer position needs to be comprehensively considered. The position of the chamfer is shown in Figure 3. From the transverse direction, the middle shell structure is used for loading goods, and the side cabins are used as ballast tanks or other cabins. The cross section of the inner shell structure is shown in Figure 4.

To establish a parametric model of the inner shell structure, the cross-sectional area expression equation at the $i$-th chamfer is as equation (1).

$$
A_{i}=\left(S W_{2}, S H_{1}, S H_{2}, S H_{3}, b\right)
$$

where $S W_{2}$ is the inner shell width, $S H_{1}$ is double bottom height, $\mathrm{SH}_{2}$ is side shell height, $S H_{3}$ is bottom oblique angle, $b$ is Flat keel half width.

\section{Mathematical model}

\subsection{Objective function}

Considering the structural specificity of unmanned ships and the possible conventions for the safety of unmanned ships in the future, unmanned ships must have higher safety during navigation than manned ships (Hooydonk, 2014). So capacity, bending moment and immersion factor are taken as the objective functions from the perspective of safety and economy.

\section{1) Cabin capacity}

In addition to safety, economics is also to be considered. At present, Frijters (2017) has analyzed the economic performance of unmanned ships in the future. During the 25-year operation period, the labor cost of unmanned ships is the biggest contributor to cost savings, but the crew on the large cargo ships are relatively less, the contribution of staffing costs to total cost is less. Therefore, for large cargo ships, the personnel cost is slightly reduced, however, since the unmanned ship needs to be equipped with equipment for network communication or sensing alarm, the total cost is increased, so that the economic performance of the entire unmanned ship cannot be determined. The subdivision layout design of the unmanned ship can obtain the largest possible volume to improve the economy. Therefore, the maximization of ship cabin capacity is the primary objective of multi-objective optimization of unmanned ships.

Based on the parametric design method of the inner shell structure, the cargo tank volume can be regarded as the integral of each cross section along the length of the ship.

The calculation method of the cargo tank volume is shown in equation (2).

$$
V=\sum_{i=1}^{n} V_{i}
$$

where $V_{i}$ is the volume of the $i-t h$ compartment. $V$ is the total volume. According to the inner shell 
structural parameters, the function of the design parameters is established along the $\mathrm{X}$-axis direction. The inner shell structures of the cross-sections at the ends of the $i-t h$ cargo tank are respectively $S_{m}$ and $S_{n}$, and $S_{n}$ is closer to the middle-cross section than $S_{m} . S_{m}$ and $S_{n}$ are shown in equation (3).

$$
\begin{aligned}
& S_{m}=\left(S W_{2 m}, S H_{1 m}, S H_{2 m}, S H_{3 m}, b\right) \\
& S_{n}=\left(S W_{2 n}, S H_{1 n}, S H_{2 n}, S H_{3 n}, b\right)
\end{aligned}
$$

Since the cross-sectional shape of the unmanned ship is different from that of the common cargo ship, the cross section will be regarded as four parts A1, A2, A3 and A4 shown in Figure 4 and the calculation equation of the cross-sectional area is in equation (4).

$$
\text { Area }=2 \times\left(b \times S H_{3}+S H_{3} \cdot\left(S W_{2}-b\right) \cdot 0.5+S H_{3} \cdot S W_{2}+\frac{1}{8} \cdot\left(S W_{2}^{2}+1\right)^{2} \cdot \arcsin \frac{2 S W_{2}}{S W_{2}^{2}+1}-\frac{S W_{2} \cdot\left(S W_{2}^{2}-1\right)}{4}\right)
$$

In the longitudinal direction, the design parameters along the $\mathrm{X}$-axis direction between two chamfer are calculated with linear interpolation shown in equation (5), linear interpolation is shown in Figure 5.

$$
\begin{aligned}
& S W_{2}(x)=\left(x-1_{m}\right) \times\left(S W_{2 n}-S W_{2 m}\right) /\left(l_{n}-l_{m}\right)+S W_{2 m} \\
& S H_{1}(x)=\left(x-1_{m}\right) \times\left(S H_{1 n}-S H_{1 m}\right) /\left(l_{n}-l_{m}\right)+S H_{1 m} \\
& S H_{2}(x)=\left(x-1_{m}\right) \times\left(S H_{2 n}-S H_{2 m}\right) /\left(l_{n}-l_{m}\right)+S H_{2 m} \\
& S H_{3}(x)=\left(x-1_{m}\right) \times\left(S H_{3 n}-S H_{3 m}\right) /\left(l_{n}-l_{m}\right)+S H_{3 m}
\end{aligned}
$$

By substituting equation (5) into equation (4), a function of the sectional cross-sectional area along the $\mathrm{X}$-axis direction can be obtained in equation (6).

$$
\operatorname{Area}_{\mathrm{i}}(x)=2 \times\left[\begin{array}{l}
b \times S H_{3}(x)+S H_{3}(x) \cdot\left(S W_{2}(x)-b\right) \cdot 0.5+S H_{2}(x) \cdot S W_{2}(x) \\
+1 / 8 \cdot\left(S W_{2}(x)^{2}+1\right)^{2} \cdot \arcsin \frac{2 S W_{2}(x)}{S W_{2}(x)^{2}+1}-\frac{S W_{2}(x) \cdot\left(S W_{2}(x)^{2}-1\right)}{4}
\end{array}\right]
$$

The volume is obtained by integrating the cross-sectional area of equation (6), and the expression is as shown in equation (7).

$$
V_{i}=\int_{l_{m}}^{l_{n}} \operatorname{Area}_{i}(x) d x
$$

\section{2) Bending Moment of full load}

During the calculation of the total longitudinal strength, the hull is usually simplified into a hollow thin-walled beam. When the ship is fully loaded, the hull girder is subjected to engine room pressure, cargo hold pressure, its own structural gravity and support from the water. The ship will have a more dangerous sagging state. For unmanned ships, the dangerous situation is similar. The unmanned ship in this paper has a large change in the bottom and the camber compared with the parent ship. Hao (2010) and Kotinis (2005) showed that the stress of the main components of the V-type non-ballasted water hull are larger than that of the parent ship. Keeping the maximum bending moment as small as possible is the second objective of this paper.

For the cargo holds of an unmanned ship, the length of each cargo hold is not the same, and the position of the transverse bulkhead is different, so the position and the value of the maximum bending moment are different. Analysis of the bending moment principle, using MATLAB to solve the ship bending moment calculation equation in this paper. The bending moment calculation principle is shown in Figure 
6.

Figure 6 shows the force of the cargo holds on the hull girder under full load conditions. In the figure, p1-p7 are the mass of each transverse bulkhead, $X_{1}-X_{7}$ are the longitudinal coordinate of each bulkhead, and $\mathrm{q}$ is the pressure of cargo oil within the unit length of the cargo area. And then we can obtain the deflection of any point on the hull girder as equation (8):

$$
\nu=v_{A P}+\theta_{A P} x+\frac{M_{A P} x^{2}}{2 E I}+\frac{N_{A P} x^{3}}{6 E I}+\left\|x_{x_{1}} \frac{p(1)\left(x-X_{1}\right)^{3}}{6 E I}+\right\| x_{x_{2}} \frac{p(2)\left(x-X_{2}\right)^{3}}{6 E I}+\ldots+\| x_{n} \frac{p(n)\left(x-X_{n}\right)^{3}}{6 E I}+\iiint_{X_{1}}^{x} \frac{q}{E I} d x^{4}
$$

where $v$ is the deflection, $\theta$ is section rotation angle, $B M$ is bending moment, $N$ is shear force, and the symbol $\|_{x_{n}}$ works when $x>X_{n}$.

Assume that the ship's constraints at the end of the perpendicular are freely supported, and the constraints are shown in equation (9).

$$
v_{A P}=0, v_{F P}=0, B M_{A P}=0, B M_{F P}=0
$$

Substitute the constraint condition (9) into the equation (8) to get equation (10).

$$
\nu=\theta_{A P} x+\frac{N_{A P} x^{3}}{6 E I}+\left\|x_{x_{1}} \frac{p(1)\left(x-X_{1}\right)^{3}}{6 E I}+\right\| x_{x_{2}} \frac{p(2)\left(x-X_{2}\right)^{3}}{6 E I}+\ldots+\| x_{x} \frac{p(n)\left(x-X_{n}\right)^{3}}{6 E I}+\iiint_{X_{1}}^{x} \frac{q}{E I} d x^{4}
$$

The bending moment of the cargo area at longitudinal coordinate $x$ is shown in equation (11).

$$
B M=E I v^{\prime \prime}=N_{A P} x+\left\|_{x_{1}} p(1)\left(x-X_{1}\right)^{3}+\right\|_{x_{2}} p(2)\left(x-X_{2}\right)^{3}+\ldots+\|_{x_{n}} p(n)\left(x-X_{n}\right)^{3}+\int_{X_{1}}^{x} d x^{2}
$$

where $p(1)-p(n)$ is the mass of each bulkhead (t), calculated from the volume and density of each bulkhead, $X_{1}-X_{n}$ are the longitudinal coordinate positions of each bulkhead and are the design variables of multi-objective optimization, $N_{A P}$ is the sheer force of the beam section at the stern perpendicular can be obtained by using the constraints.

When $B M_{A P}=0$,

$$
\begin{gathered}
\Rightarrow N_{A P} L+\left\|_{X_{1}} p(1)\left(L-X_{1}\right)+\right\|_{X_{2}} p(2)\left(L-X_{2}\right)+\ldots \|_{X_{7}} p(7)\left(L-X_{7}\right)+\frac{1}{2} q\left(X_{7}-X_{1}\right)^{2}=0 \\
\Rightarrow N_{A P} L+(p(1)+p(2)+\ldots+p(7)) L+\frac{1}{2} q\left(X_{7}-X_{1}\right)^{2}-\left[p(1) X_{1}+p(2) X_{2}+\ldots+p(7) X_{7}\right]=0 \\
N_{A P}=\frac{\sum_{i=1}^{7} p(i) X_{i}-\sum_{i=1}^{7} p(i) \cdot L-\frac{1}{2} q\left(X_{7}-X_{1}\right)^{2}}{L}
\end{gathered}
$$

The maximum bending moment usually occurs in the middle of each cargo hold. Due to the uncertainty of the design variable $x$, the calculation of the bending moment of the cargo area is carried out by 
selecting three compartments in the middle part of the cargo area. The maximum bending moment occurring at all points is the maximum bending moment of the entire cargo area. In this paper, bending moment is calculated at three cargo holds which near to the stern part and each compartment is divided into 30 points in length. The discrete schematic is shown in Figure 7.

\section{3) Immersion factor}

Based on the structural particularity of unmanned ships and the possible conventions for the safety of unmanned ships in the future, the safety requirements for unmanned ships is higher than that of manned ships. For the unmanned oil tankers proposed in this paper, the immersion of the ship after damage is more important. Especially when the width of the ballast tank changes, the probability of damage to the inner shell is greatly increased. The probability of water immersion after the damage has an important role in the stability and safety of the ship. To minimize the immersion factor as much as possible is the third objective in this paper.

For the damage stability calculation of the unmanned ship, probability damage stability method is used in this paper (CCS,2009; Wang,2011; Szulczewski, 2018).

If the damage only involves a single zone:

$$
p_{i}=\left(x 1_{\mathrm{j}}, x 2_{\mathrm{j}}\right) \cdot\left[r\left(x 1_{\mathrm{j}}, x 2_{\mathrm{j}}, b_{k}\right)-r\left(x 1_{\mathrm{j}}, x 2_{\mathrm{j}}, b_{k-1}\right)\right]
$$

If the damage involves two adjacent areas:

$$
\begin{aligned}
& p_{i}=p\left(x 1_{j}, x 2_{j+1}\right) \cdot\left[r\left(x 1_{j}, x 2_{j+1}, b_{k}\right)-r\left(x 1_{j}, x 2_{j+1}, b_{k-1}\right)\right] \\
& -p\left(x 1_{j}, x 2_{j}\right) \cdot\left[r\left(x 1_{j}, x 2_{j}, b_{k}\right)-r\left(x 1_{j}, x 2_{j}, b_{k-1}\right)\right] \\
& -p\left(x 1_{j+1}, x 2_{j+1}\right) \cdot\left[r\left(x 1_{j+1}, x 2_{j+1}, b_{k}\right)-r\left(x 1_{j+1}, x 2_{j+1}, b_{k-1}\right)\right]
\end{aligned}
$$

If damage involves three or more adjacent areas:

$$
\begin{aligned}
& p_{i}=p\left(x 1_{j}, x 2_{j+n-1}\right) \cdot\left[r\left(x 1_{j}, x 2_{j+n-1}, b_{k}\right)-r\left(x 1_{j}, x 2_{j+n-1}, b_{k-1}\right)\right] \\
& -p\left(x 1_{j}, x 2_{j+n-2}\right) \cdot\left[r\left(x 1_{j}, x 2_{j+n-2}, b_{k}\right)-r\left(x 1_{j}, x 2_{j+n-2}, b_{k-1}\right)\right] \\
& -p\left(x 1_{j+1}, x 2_{j+n-1}\right) \cdot\left[r\left(x 1_{j+1}, x 2_{j+n-1}, b_{k}\right)-r\left(x 1_{j+1}, x 2_{j+n-1}, b_{k-1}\right)\right] \\
& -p\left(x 1_{j+1}, x 2_{j+n-2}\right) \cdot\left[r\left(x 1_{j+1}, x 2_{j+n-1}, b_{k}\right)-r\left(x 1_{j+1}, x 2_{j+n-1}, b_{k-1}\right)\right]
\end{aligned}
$$

where $p_{i}$ is probability factor after damage and water immersion; $j$ is the last damage zone number within the damage range starting at 1 in the stern; $n$ is the number of the adjacent damaged area within the damage range; $k$ is the specific longitudinal bulkhead number of the transverse penetrating barrier of the damaged area, counted in order from the hull to the centerline, $k=0$ at the shell; $x 1$ is the distance from the rear end of Ls to the back end of the area under consideration; $x 2$ is the distance from the rear end of Ls to the front end of the area under consideration; $b$ is the average transverse distance $(\mathrm{m})$ between the hull and the assumed vertical plane at the deepest subdivision load line at the vertical centerline;

The coefficient $p(x 1, x 2)$ is calculated according to the following equation.

If the boundary of the cabin does not coincide with the rear-end or front-end point: 
$J \leq J_{k} \quad:$

$$
p(x 1, x 2)=p 1=\frac{1}{6} J^{2}\left(b_{11} J+3 b_{12}\right)
$$

$J>J_{k}:$

$$
\begin{aligned}
p(x 1, x 2)=p 2= & -\frac{1}{3} b_{11} J_{k}{ }^{3}+\frac{1}{2}\left(b_{11} J-b_{12}\right) J_{k}{ }^{2}+b_{12} J J_{k}-\frac{1}{3} b_{21}\left(J_{n}{ }^{3}-J_{k}{ }^{3}\right) \\
& +\frac{1}{2}\left(b_{21} J-b_{22}\right)\left(J_{n}{ }^{2}-J_{k}{ }^{2}\right)+b_{22} J\left(J_{n}-J_{k}\right)
\end{aligned}
$$

If the rear boundary of the cabin is coincident with the rear end point or the front boundary of the cabin considered coincides with the front-end point:

$$
J \leq J_{k} \quad:
$$

$$
p(x 1, x 2)=\frac{1}{2}\left(p_{1}+J\right)
$$

$J>J_{k}:$

$$
p(x 1, x 2)=\frac{1}{2}\left(p_{2}+J\right)
$$

If the considered cabin or group extends to the entire subdivision length (Ls):

$$
p(x 1, x 2)=1
$$

Coefficient $r(x 1, x 2, b)$ is calculated according to the following equation:

$$
r(x 1, x 2, b)=1-(1-C) \cdot\left[1-\frac{G}{p(x 1, x 2)}\right]
$$

Where $C=12 \cdot J_{b} \cdot\left(-45 \cdot J_{b}+4\right)$ then

$$
J_{b}=\frac{b}{15 \cdot B}
$$

If the cabin or cabin group is extended to the entire subdivision length (Ls):

$$
G=G_{1}=\frac{1}{2} b_{11} J_{b}^{2}+b_{12} J_{b}
$$

If the boundaries of the cabin or cabin group considered do not coincide with the rear or front points:

$$
G=G_{2}=-\frac{1}{3} b_{11} J_{0}{ }^{3}+\frac{1}{2}\left(b_{11} J-b_{12}\right) J_{0}{ }^{2}+b_{12} J J_{0}
$$

If the rear boundary of the cabin or group considered is coincident with the rear end point or the front boundary of the considered cabin or cabin group coincides with the front point:

$$
G=\frac{1}{2}\left(G_{2}+G_{1} \cdot J\right)
$$

According to the calculation principle, the immersion factor calculation process is programmed by MATLAB. 


\subsection{Design variable}

For the cabin optimization problem of the non-ballasted water unmanned ship proposed in this paper, based on the above three objective functions, the longitudinal position of the transverse bulkhead $X_{1}, X_{2}, X_{3}, X_{4}, X_{5}, X_{6}, X_{7}$ and the inner shell basic elements on each cross section $S W_{2 i}, S H_{1 i}, S H_{2 i}, S H_{3 i}$ are selected as the design variables.

\subsection{Design restrictions condition}

In the process of multi-objective optimization, it is necessary to set constraints on design variables in order to limit their values within a reasonable range. In addition, the re-adjustment of the design parameters of the inner shell structure will redistribute the ship's cargo hold volume, resulting in changes in ship's loading conditions. Therefore, in the process of optimization calculation, it is necessary to calculate the floating state and stability of ships under various loading conditions, and check whether the subdivision layout design meets the requirements of relevant conventions and norms (Chen, 2010).

(1) From $X_{1}$ to $X_{7}$ the seven design variables are the longitudinal position of the transverse bulkhead in the cargo area. Since the total length of the cargo area is constant, the sum of these variables is constant. In addition, in order to speed up the optimization, improve the optimization efficiency and avoid falling into the local optimal solution, based on the specification of the ship cargo compartment length ( IMO,2016), the range of each design variable is set to $\pm 4 \mathrm{~m}$.

(2) The hull shell structure constraints on design variables: the double bottom height $h$ and the inner shell half width $W$ can get through the damage stability related specifications (CCS, 2012).

$\mathrm{W}$ is the smaller of $W=0.5+\frac{D W}{20000} \quad$ and $2.0 \mathrm{~m}$ and $\mathrm{W} \geq 1.0 \mathrm{~m}$

$\mathrm{H}$ is the smaller of $h=\frac{B}{15}$ and $2.0 \mathrm{~m}$ and $h \geq 1.0 \mathrm{~m}$

(3) According to "Rules for Building and Classing Steel Vessels 2012" and MARPOL 73/78. The permissible values of performance indicators should meet the specification requirements. At the same time, the draught at the perpendiculars of the stern cannot less than the draft water required for full immersion of propellers.

$$
G M(x) \geq G M_{\text {perm }}, d(x) \geq d_{\text {perm }}, 0 \leq \operatorname{Trim}(x) \leq \operatorname{Trim}_{\text {perm }}, d r_{A P}(x) \geq d r_{A P-\text { perm }}
$$

Where $G M(x)$ is initial stability height; $d(x)$ is average draught; $\operatorname{Trim}(x)$ is trim value; $d r_{A P}(x)$ is draught at the position of the ship's stern line; $G M_{\text {perm }}, d_{\text {perm }}, T r i m_{\text {perm }}, d r_{A P-p e r m}$ is the specification permissible values, according to specification, the permissible values are shown in Table 2.

(4) The constraint of the maximum longitudinal bending moments (BM) that occurs in the whole exchanging process.

$$
B M_{\max } \leq B M_{\text {perm }}
$$

where, $B M_{\text {perm }}$ is the permissible bending moment and $B M_{\max }$ is the maximum value of the 
longitudinal bending moment in hogging or in sagging that occurs in the whole exchanging process.

\section{Application and improvement of particle swarm optimization}

\subsection{Principle of particle swarm optimization}

Particle swarm optimization proposed by Kennedy et al. $(1995,1997)$ is an artificial intelligence algorithm. In the process of flying to a habitat or looking for food, any bird has no specific target at the beginning until a bird finds a habitat or food, that is, the expected value of the habitat or food location information is higher than the expected value of other peers in the group. The bird near it knows the target information after interacting with it. Gradually, other birds in the group will adjust their flight path to the habitat or food location, and then naturally form a flock of birds.

The individual of the population is no longer a bird, but is regarded as a particle without mass and volume when dealt with the optimization problem. Suppose there are m particles in the group. When facing the n-dimensional problem, each particle flies in the n-dimensional search space at a certain speed. For the $t-t h$ iteration, the position of the $i-t h$ particle is $X_{i}^{t}=\left(x_{i 1}^{t}, x_{i 2}^{t}, \mathrm{~L} x_{i n}^{t}\right), i=1,2, \mathrm{~K}, m$ and its flight speed is $V_{i}^{t}=\left(v_{i t}^{t}, v_{i 2}^{t}, \mathrm{~L} v_{i n}^{t}\right), i=1,2, \mathrm{~L}, m, \mathrm{i}=1,2, \ldots, \mathrm{m}$. The update of the flight position and velocity in the $j-t h(j=1,2, \mathrm{~L}, n)$ dimensional subspace of particle $i$ at the $t-t h$ iteration is shown in the equation (31).

$$
\begin{gathered}
x_{i j}^{t+1}=x_{i j}^{t}+v_{i j}^{t+1} \\
v_{i j}^{t+1}=\varpi v_{i j}^{t}+c_{1} r_{1}\left(p_{i j}-x_{i j}^{t}\right)+c_{2} r_{2}\left(g_{j}-x_{i j}^{t}\right) \\
v_{i j}^{t+1}=\left\{\begin{array}{l}
v_{\max }, v_{i j}^{t+1}>v_{\max } \\
-v_{\max }, v_{i j}^{t+1}<-v_{\max }
\end{array}\right.
\end{gathered}
$$

where $\omega$ is the inertia weights; $c_{1}, c_{2}$ are the learning coefficients of "self-cognition" and "social cognition", $r_{1}$ and $r_{2}$ are $[0,1]$ random numbers. The particle $i$ adjusts its own speed according to its historical optimal value $p_{i j}$ and the population optimal value $g_{j}$. The optimal value $p_{i j}$ and $g_{j}$ are judged by the fitness function. In this paper, three objective functions are taken as the fitness function.

\subsection{Multi-objective particle swarm optimization}

Although the successful application of particle swarm optimization algorithm in many single-objective optimization problems illustrates the effectiveness of the algorithm, the particle swarm optimization algorithm cannot be directly applied to multi-objective optimization problems (Qiu et al,2019), because multi-objective optimization problems and single-objective optimization problems have essential difference. Particle swarm algorithm does not share information between chromosomes like genetic algorithm. The information in particle swarm algorithm is given by the best particles and other individuals follow the best particles to quickly converge to a dot. Therefore, the multi-objective optimization problem with the algorithm will easily converge to a local region of the non-inferior optimal domain (Shi,2001; Bornapour,2019). There are also many improvements need to be considered, 
including:

(1) How to judge which is better between two particles;

(2) Method of selecting individual extremum and global extremum;

(3) How to avoid falling into local optimum situation.

\subsection{Improvement of particle swarm optimization}

1) Analysis of the specificity

The hull shape limits the maximum volume of the internal structure. Since the position of each transverse bulkhead $X_{i}$ is uncertain, the design variables at each transverse bulkhead $S W_{2}, S_{1}, S H_{2}, S H_{3}$ are also uncertain. In this case, the longitudinal position of each bulkhead is determined first, and then the corresponding design variables at each bulkhead are determined. It determines the functional relationship between the transverse design variables and the longitudinal position. The determination of the functional relationship is mainly based on the position of each chamfer of the hull. Since the planar design is adopted between the two adjacent chamfers, the transverse design variable of the bulkhead between any two chamfers can be linearly interpolated.

2) Internal and external nested PSO

The first stage is the determination of the longitudinal position of each transverse bulkhead. The second stage is the selection of the transverse design variables corresponding to each bulkhead after the determination of the position of each bulkhead. For the staged optimization problem, the internal and external nested particle swarm optimization algorithm is used to solve the problem. The longitudinal position $X_{i}$ of each bulkhead is set as the external design variable. The calculation of the internal algorithm is mainly to seek the values of the four transverse design variables under a certain set of $X_{i}$.

The improved multi-objective PSO algorithm (Cooren et al. 2011) constructs a non-dominated solution set based on the pareto dominance relation. Applies the congestion degree to improve the global extremum selection method to avoid falling into the local non-inferior optimal solution, and a random selection strategy grouping method is proposed to speed up the algorithm.

3) Procedure of the algorithm

Procedure of the algorithm is illustrated in Figure 8 and described as follows:

Step 1.Input ship parameters, initialize the population, and set the count number $i=0$.

Step 2. Compute the objectives and constraints of all the individuals.

Step 3. Update external archives and use the non-dominated solution comparison strategy to judge and eliminate the second generated solution and the non-inferior solution in the current archives.

Step 4. The crowding distance of global particles is calculated and the selection strategy of global optimal particles are selected.

Step 5. The individual optimum and global optimum values of this generation are achieved.

Step 6.Particle position perturbation.

Step 7.Update particle's velocity and position.

Step 8. Judge whether the termination criterion is satisfied, if yes, go to Step 8; if not, go to Step 2.

Step 9. Output the Pareto set.

In MATLAB, particle swarm optimization combined with subdivision optimization functions call flow is illustrated in Figure 9 and described as follows:

Step 1. The main function: set the basic parameters of the outer particle swarm algorithm.

Step 2. The inner nested function: set three sub-functions, namely the cabin capacity, bending moment 
and water immersion factor.

Step 3. Weight center of gravity calculation function: compute the weight and center of gravity of the ship under each subdivision scheme.

Step 4. Load calculation function: calculate the floating and stability of the ship under each subdivision scheme, mainly including the ship's trim value and metacentric height. Using the weight center of gravity value obtained in step 3 and interpolation calculation of the hydrostatic curve table to calculate the value of the trim value and GM under the current scheme;

Step 5. Non-dominated solution seeking function: judge the left non-dominated solution and eliminate the dominant solution.

Step 6. Congestion distance calculation function: select the global optimal solution.

Step 7. Particle update function: update particle velocity and particle position.

\subsection{Results and discussion}

The outer layer 600 particles and the inner layer has 100 particles, the inertia weight is 1.04 , and the learning factor is 2 ; the iterations number of outer layer and inner layer are 100.The results are shown in Figure 10.

In the frontier solution, the point closest to the origin is set as the optimal solution. Since the number of optimization solutions is large and the distance is too close to be clearly distinguished. According to the characteristics of the multi-objective optimization problem in this paper, the minimum value from the origin is selected to determine the optimal scheme, and the normalization is performed by min-max. The top five cabin subdivision schemes are shown in Table 3 and the top five objective function values are shown Table 4 .

The min-max method is a linear transformation of the original data, causing the result to fall between $[0,1]$. The conversion function is as equation (33).

$$
x^{*}=\frac{x-\min }{\max -\min }
$$

where max is the maximum value of the sample data, $\min$ is the minimum value of the sample data.

Result analysis :

(1) As can be seen from Figure 10, only a few dozen frontier solutions have been generated. The number of particles does not match the number of corresponding pareto fronts and the number of pareto fronts is significantly less than normal. Since the ship in this paper is the first attempt to adopt the overall layout of the unmanned ship without ballast water design, the difference between the structure and the cabin layout leads to stricter constraints in the algorithm. Therefore, it is normal for the pareto frontier solution to be less in the result.

(2) The population size and number of iterations are still too small. This optimization problem includes internal and external two layers optimization. The iterations of inner layer and outer layer is 100 times. The optimization space for the inner layer is still very large and higher requirements for computers is need. 


\subsection{Method validation}

For the high-dimensional nonlinear multi-objective optimization problem, the system has many complex variables. With the concept of gray correlation degree, the complex system can be characterized by taking the parameters that can reflect the problem characteristics (Deng 1990).

The specific theory is as follows:

(1) Let the reference vector sequence be $X_{0}=\left\{\left\langle x_{0}(k) \mid k=1,2 \ldots, n\right\rangle\right\}$, whose value is the optimal value of each function calculated by the single-objective particle swarm optimization algorithm, as a comparison sequence of the objective function values calculated by each set of design variables;

(2) Construct the fitness solution, and substitute each set of design variables into the fitness function to obtain the target vector sequence $X_{j}=\left\{\left\langle x_{j}(k) \mid j=1,2 \ldots, m\right\rangle\right\}$, where $\mathrm{k}$ is the number of target vectors and $\mathrm{j}$ is the serial number.

(3) The gray correlation coefficient of $X_{j}$ relative to $X_{0}$ is shown in equation (34).

$$
\varepsilon_{k}=\frac{\min \min \left|x_{0}(k)-x_{j}(k)\right|+\zeta \min \min \left|x_{0}(k)-x(k)\right|}{\left|x_{0}(k)-x_{j}(k)\right|+\zeta \max \max \left|x_{0}(k)-x_{j}(k)\right|}
$$

The degree of relevance is shown in equation (35).

$$
Y=\frac{1}{n} \sum_{k=1}^{n} \varepsilon_{k}
$$

$X_{0}$ is a sequence of features that characterize the ideal state of the system; $X_{\mathrm{j}}$ is a sequence that characterizes the general state of the system. The higher the degree of association between $X_{0}$ and $X_{\mathrm{j}}$ the system will be closer the ideal state, that is, the optimal solution will be obtained.

The key process of the gray particle swarm algorithm is as follows.

(i)The optimal fitness values of the objective function under the corresponding constraints are respectively determined by the single-objective standard particle swarm optimization algorithm, and their optimal fitness values are regarded as the reference vector sequence $X_{0}$;

(ii) According to the actual cabin optimization problem, under various constraints, the parameters such as particle size, iteration number, position and speed are initialized, and each particle is substituted into each fitness function to obtain the initial objective value. Taking the set of values as the objective vector sequence $X_{j}$;

(iii) Find the correlation between $X_{0}$ and $X_{j}$ of each particle, set the current $X_{0}$ and its corresponding degree of association to the individual extremum of the particle as $p_{\text {best }}$, and the particle's position of the largest relevance and its relevance as the global extreme value $g_{\text {best }}$;

(iv)Update particle position, velocity, learning factor, and weight;

(v)Calculate the correlation degree of each particle, and compare it with the correlation degree corresponding to the optimal position. If it is better, save the current relevance value and the 
corresponding particle position as $p_{\text {best }}$. Compare $p_{\text {best }}$ and $g_{\text {best }}$ of all particles, if it is better, update the $p_{\text {best }}$ to global extremum and store its corresponding particle position;

(vi) Determining whether the number of iterations is within the maximum allowable number of iterations, if not, returning to step (iv) to continue the iteration; otherwise, stopping the search, outputting the global extremum;

The results are shown in Figure 11.

The optimal top five cabin subdivision scheme is shown in Table 5 and the top five objective function values are shown Table 6 .

It can be seen from Table 5 and Table 3,compared with the calculation results of the multiobjective particle swarm algorithm, for cabin volume, the values of the first five sets of solutions are significantly smaller than the multi-objective particle swarm optimization algorithm; for bending moment and immersion factor, the values of the gray particles algorithm is slightly larger than that of the multi-objective particle swarm optimization algorithm. The result of grey particle swarm optimization is obviously inferior to that of multi-objective particle swarm optimization. Although the gray particle swarm optimization algorithm is simple, its applicability to the three objective functions is not strong, and the calculation results are not better than the multi-objective optimization particle swarm optimization algorithm. The comparative analysis shows that the improved multi-objective particle swarm optimization algorithm can achieve better results.

\subsection{Comparative analysis with single objective optimization}

The three objective functions of cabin volume, bending moment and water immersion factor are calculated by standard particle swarm optimization algorithm. The results are shown in Figure 12, 13 and 14 respectively. The top five cabin subdivision scheme and corresponding objective function values are shown in Table 7,8 and 9 respectively.

Analyze the calculation results of three targets based on table 7, 8, 9.

(1) The results of the ship subdivision scheme are different based on different objective functions. For example, for "cabin" single object analysis, the extreme value selection of the two objects do not have to be as rigorous as in the multi-objective optimization. In the results of the cabin calculation, the position of the bulkheads at both ends of the ship is obviously taken as far as possible at the edge bounded at both ends to obtain the maximum capacity. The length of the cabin at the chamfers of the ship is shorter, and the length of the cabin at the parallel middle body is longer, thus maximizing to avoid the loss caused by the chamfers of the ship. Compared with the original capacity of the mother ship $39050 \mathrm{~m}^{3}$, the optimal result of this cabin optimization is about $40528 \mathrm{~m}^{3}$, an increase of $1478 \mathrm{~m}^{3}$, accounting for $3.78 \%$ of the original capacity.

(2) In the analysis of the "bending moment", the position of the bulkhead at the front and rear end of the ship is closer to the middle of the ship. This is because the concentrated and uniform compartment distribution is conducive to the reduction of the ship's bending moment, improving the structural strength of the ship and is conducive to the safety of full-load navigation. And the bending moment value of the unmanned ship is within the range specified by the existing specifications for the bending moment of the tanker, indicating that the structural strength of the unmanned ship meets the specification requirements.

(3) The single-objective calculation result value of the "immersion factor" is significantly better 
than the value in the multi-objective optimization, which is also because the single-objective analysis does not have a compromise with the other two targets. And it also indicates that the ship's water immersion probability during navigation can reach a small level. Although the unmanned ship is quite different from the ordinary ship in structural design, the safety can be fully guaranteed.

(4)The optimal subdivision scheme is compared with the original design subdivision scheme shown in Figure 15. In the figure the blue line is the bulkhead position line of "cabin capacity" as the object, the red is the bulkhead position line of "bending moment" as the object and the green is the bulkhead position line of "immersion factor" as the object. The schematic diagram of the Transverse subdivision scheme is shown in Figure 16.

(5) In order to illustrate the problem more clearly, the multi-objective particle swarm optimization scheme, the grey particle swarm optimization scheme and the single-objective cabin capacity maximization optimization scheme are compared with the original scheme, as shown in Figure 17. In the figure black lines represent the subdivision of initial design, red lines represent the result of multi-objective subdivision, green Lines Represent the results of grey particle swarm subdivision and blue lines represent subdivision results for maximizing cabin capacity.

\section{Conclusion}

In this paper, the multi-objective optimization of ship compartment division is carried out from three aspects: cabin capacity, bending moment and water immersion factor. Aiming at the particularity of the non-ballast unmanned ship, a parametric representation method for characterizing the inner shell structure of the cargo hold is proposed, and the equation for the cargo hold capacity is established. The four transverse characteristic variables of the cargo tank inner shell structure and the longitudinal position of the transverse bulkhead are used as design variables. The relevant norms and conventions are used as constraints, and the tank capacity, bending moment and water immersion factor are used as objective functions. The improved multi-objective particle swarm optimization algorithm is used to optimize the compartment division. Based on the grey relational degree theory, the multi-objective problem is transformed into a single-objective problem with grey correlation degree. The correctness and superiority of the multi-objective particle swarm optimization algorithm are verified. Finally, the three objects are separately analyzed by single object, and the single object particle swarm optimization algorithm is used to solve them separately. The optimal value and the subdivision schemes based on each object are obtained.

Ship design is a systematic project, which is a process of balancing multiple factors and multiple objectives. The ship designer emphasizes the ship's performance, such as cargo capacity, structural strength, Stability, rapidity, navigability and so on. Therefore, in the face of different types of requirements, it is necessary to analyze the various objectives of the ship from different point of view. In this paper, only three objectives are used for optimization. In the future, more performance of unmanned ships will be analyzed to explore better unmanned ship design.

\section{Acknowledgements}

This work is supported by Natural Science Foundation of China (51609031) and China Scholarship Council (No.201806575010) 
Conflicts of Interest: The authors declare no conflict of interest.

\section{References}

Anonymous.,2017. China's unmanned cargo ship R\&D technical system established. Ship and supporting,12, 90.

Bornapour, M., Khodabakhshian, A., Esmaili, M R.,2019. Optimal Multi-objective Placement of Wind Turbines Considering Voltage Stability, Total Loss and Cost Using Fuzzy Adaptive Modified Particle Swarm Optimization Algorithm.Iran J Sci Technol Trans Electr Eng,43:343-359

Boulougouris,E.K.,Papanikolaou,A.D.,Zaraphonitis,G.,2004.Optimization of arrangements of Ro-Ro passenger ships with genetic algorithms. Ship Technology Research,51(3), 99-105

Burmeister, H-C., Bruhn,W., Rødseth, Ø J., et al.,2014. Autonomous unmanned merchant vessel and its contribution towards the e-Navigation implementation: The MUNIN perspective. International Journal of e-Navigation and Maritime Economy, 1,1-13.

Cabaj,D., Pallard, S L., Ridden, D J., 2007.The efficient design of subdivision in light of SOLAS 2009 using probabilistic floodable length surfaces .RINA, Royal Institution of Naval Architects International ConferenceDesign and Operation of Passenger ships, London ,United Kingdom.

CCS.,2012. Rules for classification of sea-going steel ships.Beijing:China communication press.

Chen, J., Lin, Y., Hou, J Z., et al.,2010. Optimization of ship's subdivision arrangement for offshore sequential ballast water exchange using a non-dominated sorting genetic algorithm. Ocean Engineering,37, 978-988.

China Maritime (2018). The first unmanned container ship launched in 2018.1,73-73.

Cooren, Y., Clerc, M., Siarry, P. MO-TRIBES.,2011. An adaptive multi-objective particle swarm optimization algorithm. Computational Optimization and Applications,49 (2),379-400.

Cui,H.,Turan,O.,2010.Application of a new multi-agent based particle swarm optimization methodology in ship design.Computer-Aided Design,42(11),1013-1027.

Deng,J L.,1990. Grey System Theory Tutorial.Huazhong University of Science and Technology Press.

Frijters,T. , 2017. Future Ships Design and Cost Analysis of Unmanned Ships. MA Thesis, Delft University of Technology.

Gao, Z J., Zhang, Y J., Sun, P T., Li W H.,2017 Research summary of unmanned ship. Journal of Dalian Maritime University, 43(2), 1-7.

Gong, M H.,2013. Research on FRP fishing vessel hull subdivision parametric design and software development. MA Thesis,

Dalian university of technology.

Hooydonk, E V.,2014. The law of unmanned merchant shipping-an exploration. Journal of International Maritime Law, 20,

403-423.

Jiang, W J. Research on efficient design method of main hull arrangement.MA Thesis, Dalian university of technology.

Jing,M Y., Zhang, J N.,Zhang L., et al.,2016.Design research of tanker subdivision based on minimization of risk.Shipbuilding of China, 57(1), 186-192.

Jokioinen, E J.2016., Remote and autonomous ships the next steps. London: AAWA.

Kennedy J.,Eberhart R,.1995.A new optimizer using particle swarm theory. Proceedings of the Sixth International Symposium on Micro Machine and Human Science, Nagoya, Japan, NJ,39-43 
Kennedy, J. 1997. The particle swarm: social adaptation of knowledge. Proc. IEEE International Conference on Evolutionary Computation (Indianapolis, Indiana), IEEE Service Center, Piscataway, NJ, 303-308.

Koningh, D D., Koelman, H., Hopman, H.,2011.A novel ship subdivision method and its application in constraint management of ship layout design. Journal of ship production, 27(3),137-145.

Kotinis, M D., Parsons M P., Lamb,Thomas., et al.,2014.Development and investigation of the ballast free ship concept.Transactions of sname,112,206-240

Liu W, Liu J F.2017, The study of the development of intelligent ships and China's development strategy. Ship science and technology,39(11),189-193

IMO, 2016. Annex I of MARPOL convention.

MUNIN.2015. Research in maritime autonomous systems project results and technology potentials. MUNIN ,2015.

Ölcer, Aİ,Tuzcu C.,Turan O., 2006.An integrated multi-objective optimization and fuzzy multi-attributive group decision-making technique for subdivision arrangement of Ro-Ro vessels. Applied Soft Computing, 6,221-243

Ölcer, Aİ.,2008. A hybrid approach for multi-objective combinatorial optimization problems in ship design and shipping. Computers \& Operations Research,35.2760-2775

Pawlowski M., Laskowski A.,2014. Effect of watertight subdivision on damage stability of ro-ro ferries[J].Transactions of the Royal Institution of Naval Architects Part A:International Journal of Maritime Engineering. 156(Part A2),131-136

Perez-Arribas F.,2014. Parametric generation of planning hulls. Ocean Engineering,81:89-104

Qiu,W Z., Song X Y., Shi K Y., et al.,2019.Multi-objective optimization of semi-submersible platforms using particle swam optimization algorithm based on surrogate model. Ocean engineering,178,388-409

Rodseth Ø J, Burmeister H-C.,2012. Developments toward the unmanned ship. Proceedings of International Symposium Information on Ships-ISIS. Hamburg, Germany: ISIS.

Rodseth Ø J, Tjora Á.,2014. A system architecture for an unmanned ship. Proceedings of the 13th International Conference on Computer and IT Applications in the Maritime Industries (COMPIT). Redworth,UK:Verlag Schriftenreihe Schiffbau,2014.

Rodseth Ø J.,2017. From concept to reality: unmanned merchant ship research in Norway, 2017 IEEE Underwater Technology (UT). Busan, South Korean: IEEE.

Santos T.A.,Guedes Soares C.,2005.Multi-objective optimization of fast ferry watertight subdivision[C].12th International congress of the International Maritime Association of the Mediterranean, IMAM 2005-Maritime Transportation and Exploitation of Ocean and Coastal Resources , Lisboa, Portugal, 2005

Seamen,2017.How fast is the "unmanned ship"?http://www.ycseaman.com/bencandy.php?fid-33-id-72427-page1.html

Shi Y., Eberhart R,2001. Fussy adaptive particle swarm optimization. Proc. Congress on Evolutionary Computation, Seoul,Korea,101-106

Su, S J., Han, J., Wang T L.,2018. Influence of unmanned ship on ship design. Ship Engineering, 40(Supplement1) ,346-351

Szulczewski, P. S.,2018. Dangers arising from application of the probabilistic method (as included in SOLAS 2009 Ch. II-1) to measuring level of safety of cargo ships. International Journal of Maritime Engineering, 160,243-248

Wang, Q., 2011. SOLAS 2009 probabilistic damage stability method and application, MA Thesis, Dalian university of technology.

Yu Y.,Lin Y.,Chen M.,et al.,2015.A new method for ship inner shell optimization based on parametric technique. International Journal of Naval Architecture and Ocean Engineering.142-156 


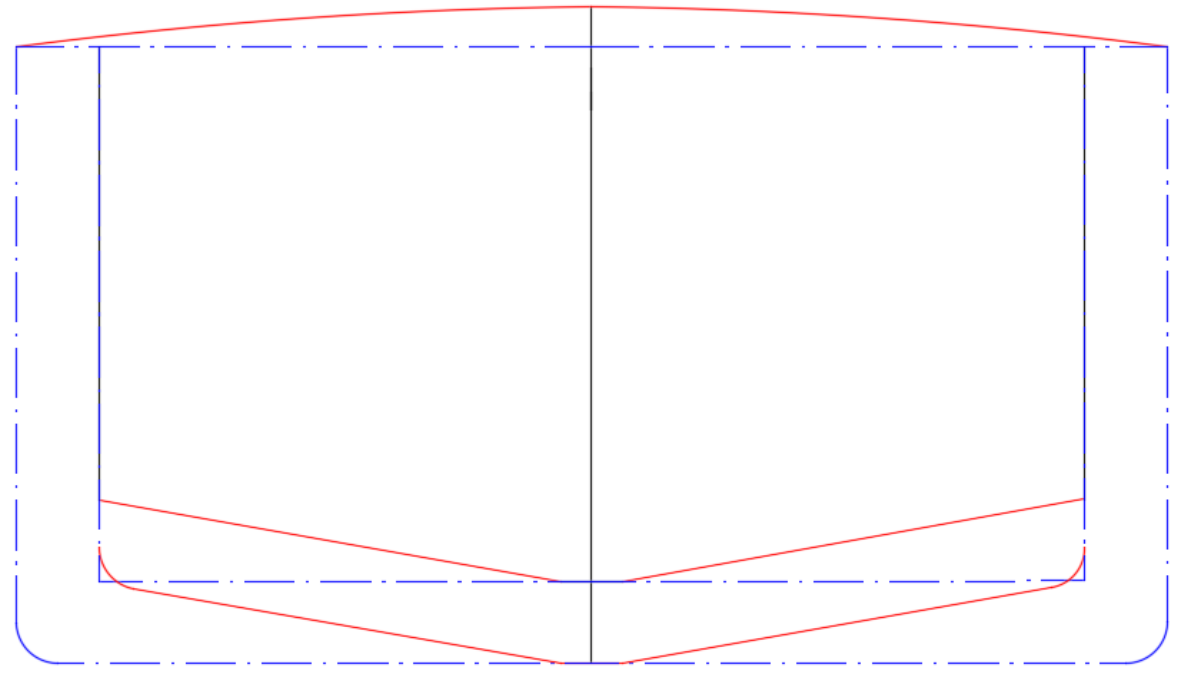

Figure 1 Comparison of mother ship and V-type unmanned ship
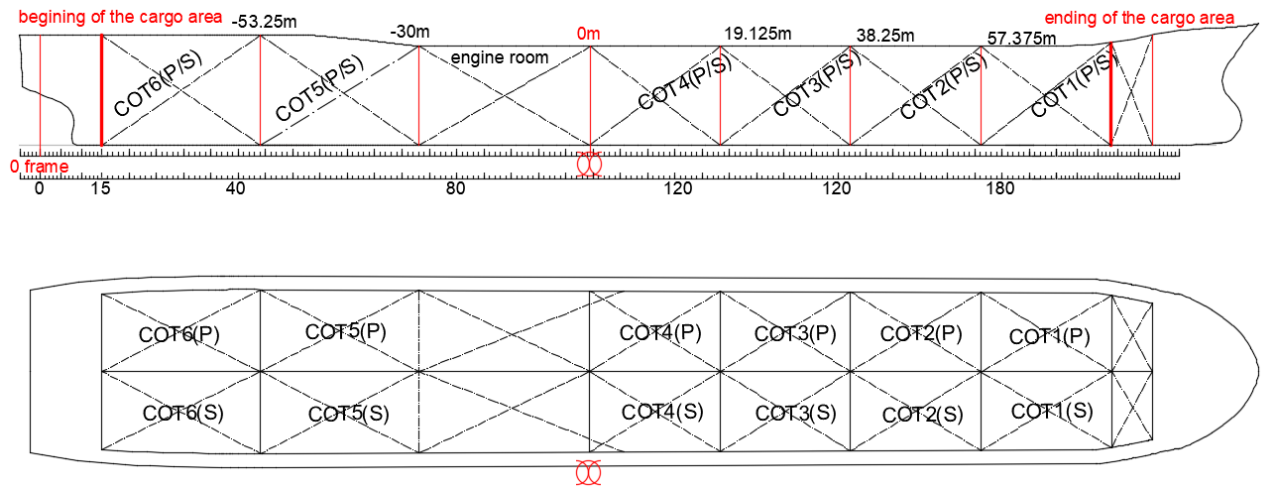

Figure 2 Schematic diagram of compartment division

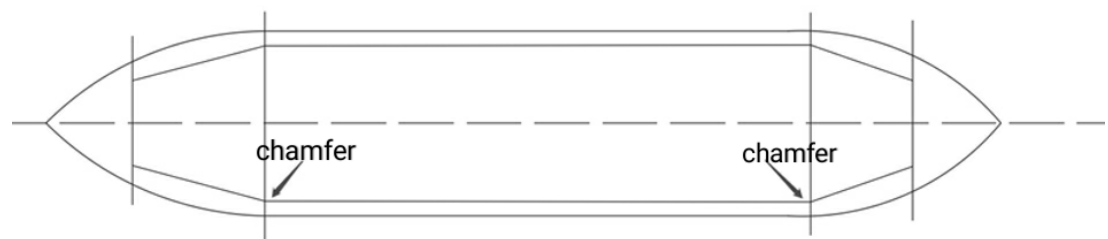

Figure 3. Schematic diagram of the corner position 


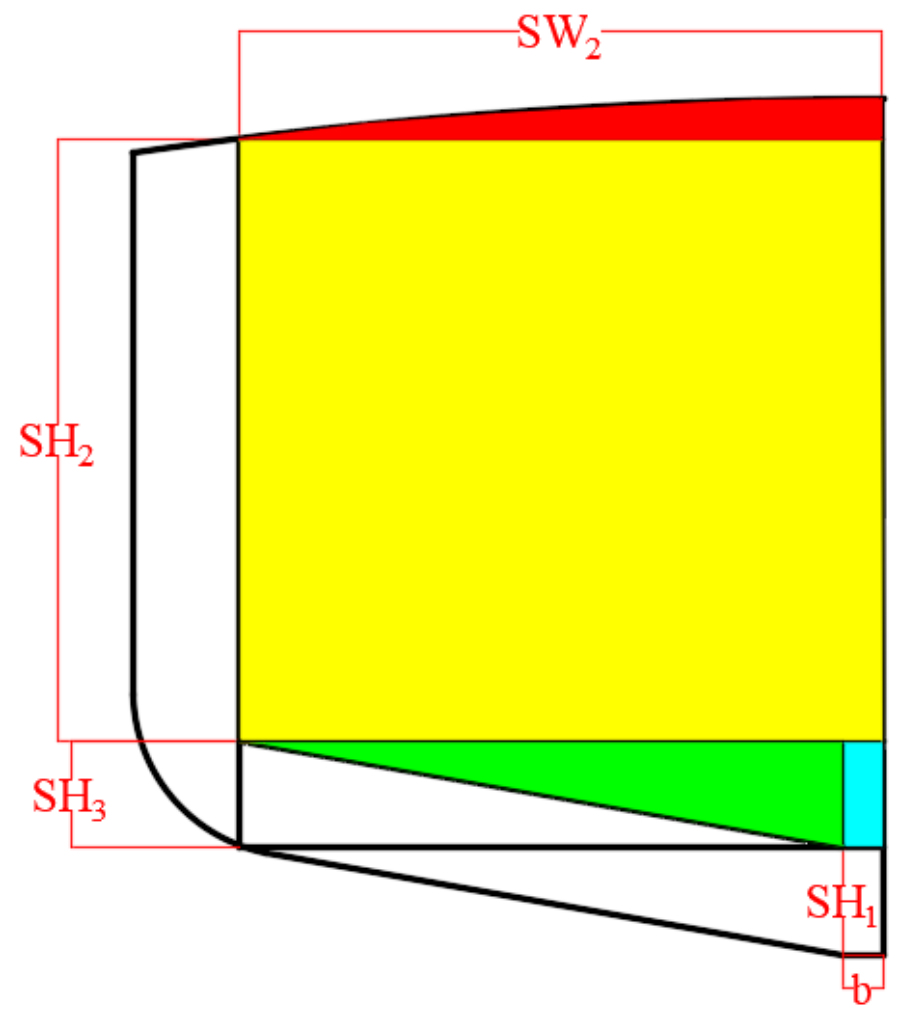

Figure 4. Internal shell cross section schematic

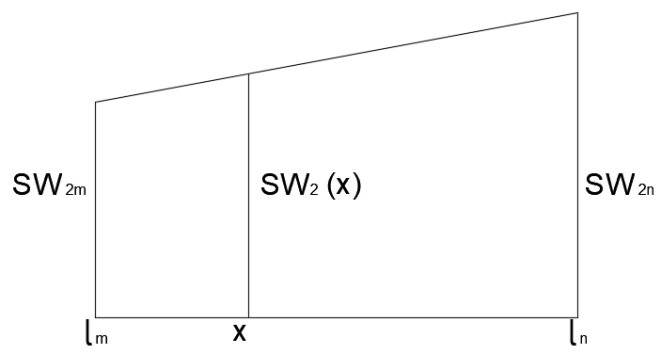

Figure 5. Linear interpolation of design parameters 

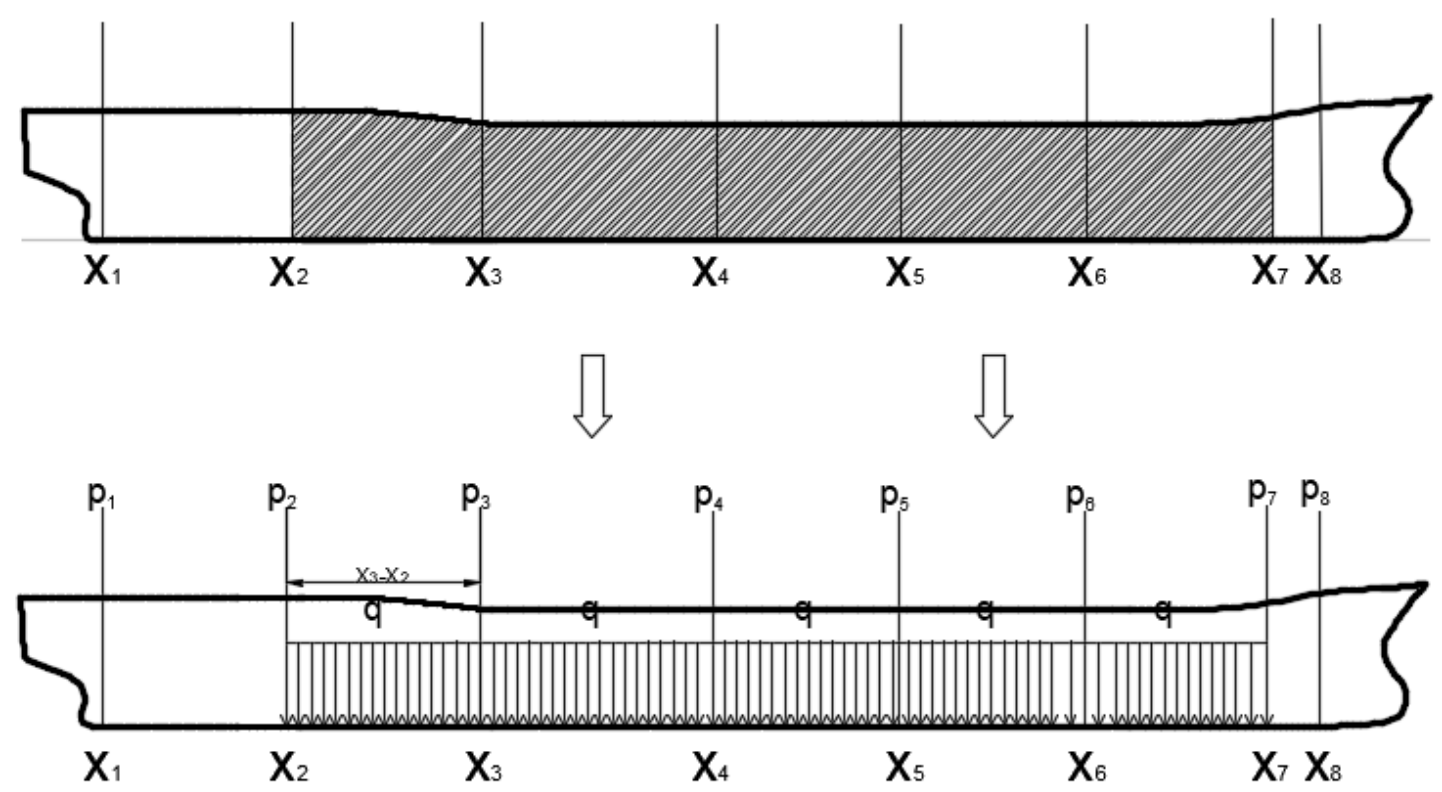

Figure 6. Effect of cargo oil and bulkhead on hull girder

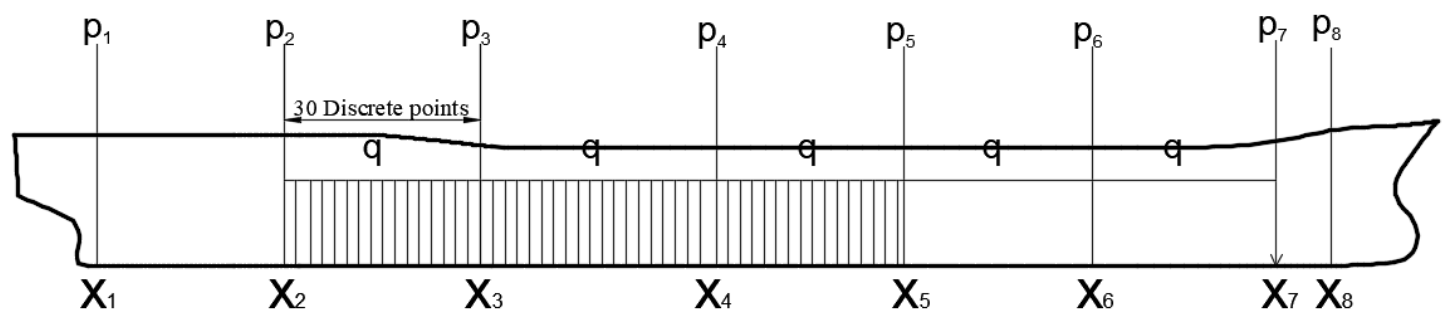

Figure 7. Bending moment calculation discrete point diagram 


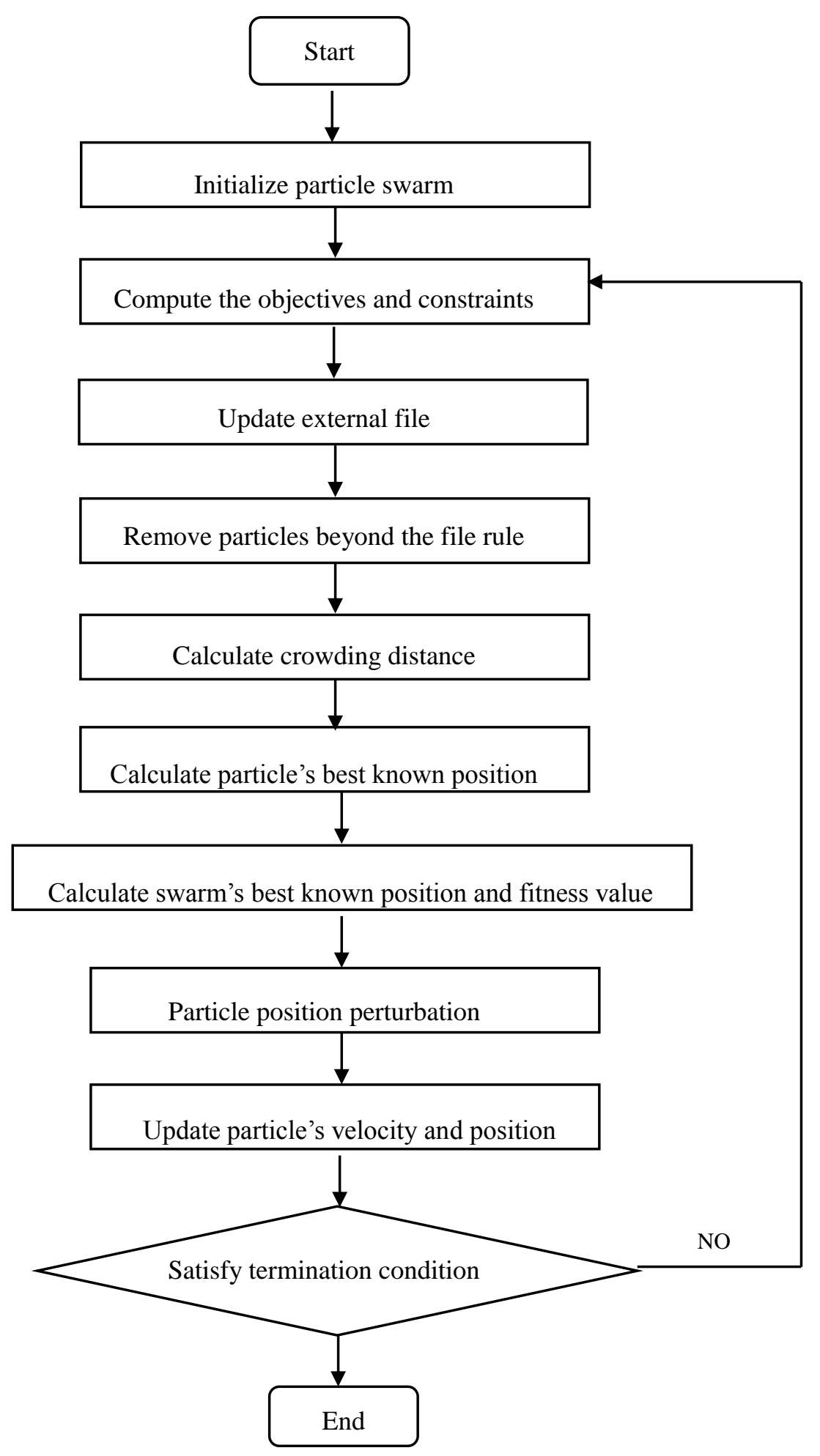

Figure 8. Procedure of the algorithm 


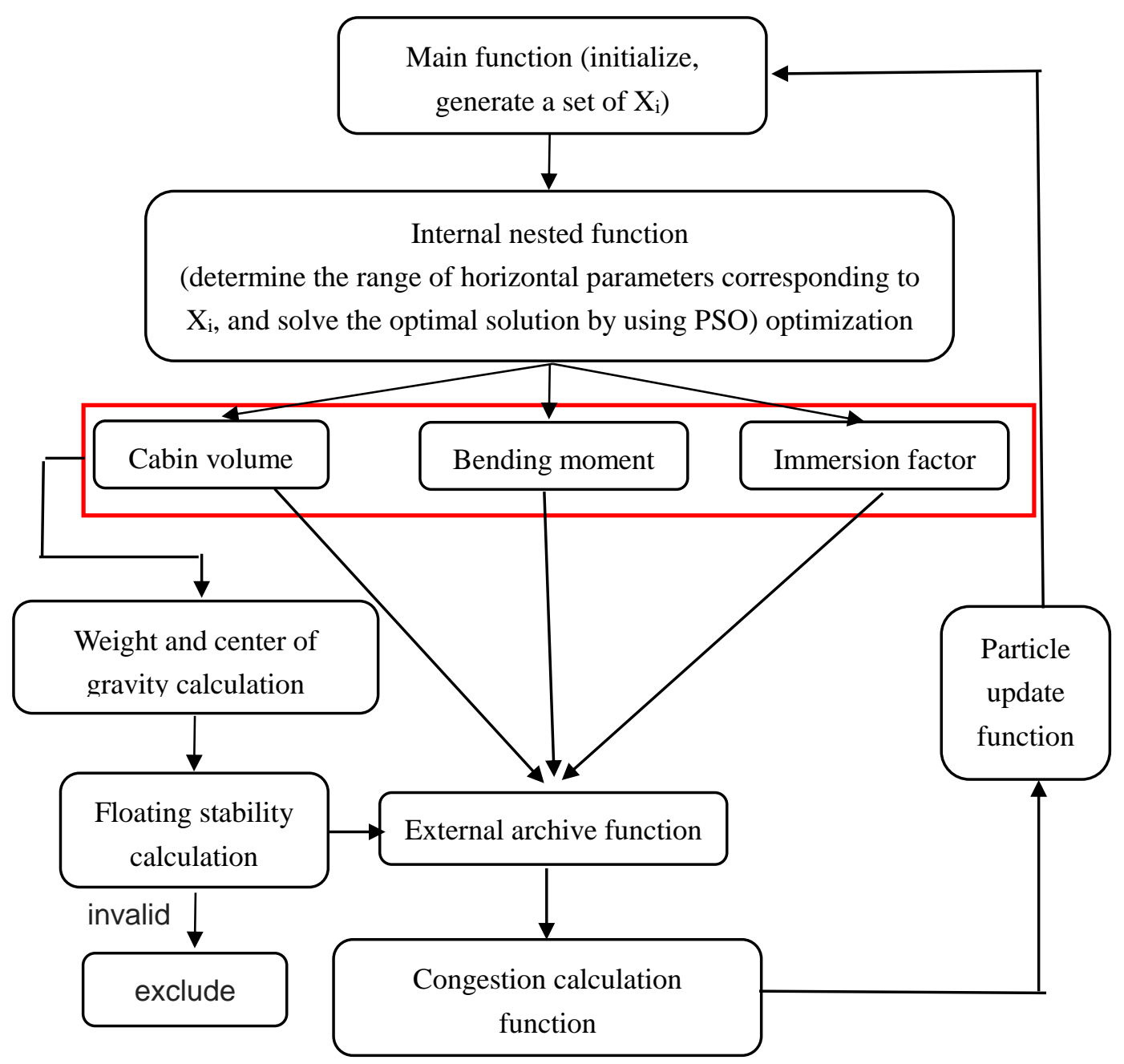

Figure 9. Function call flow chart 


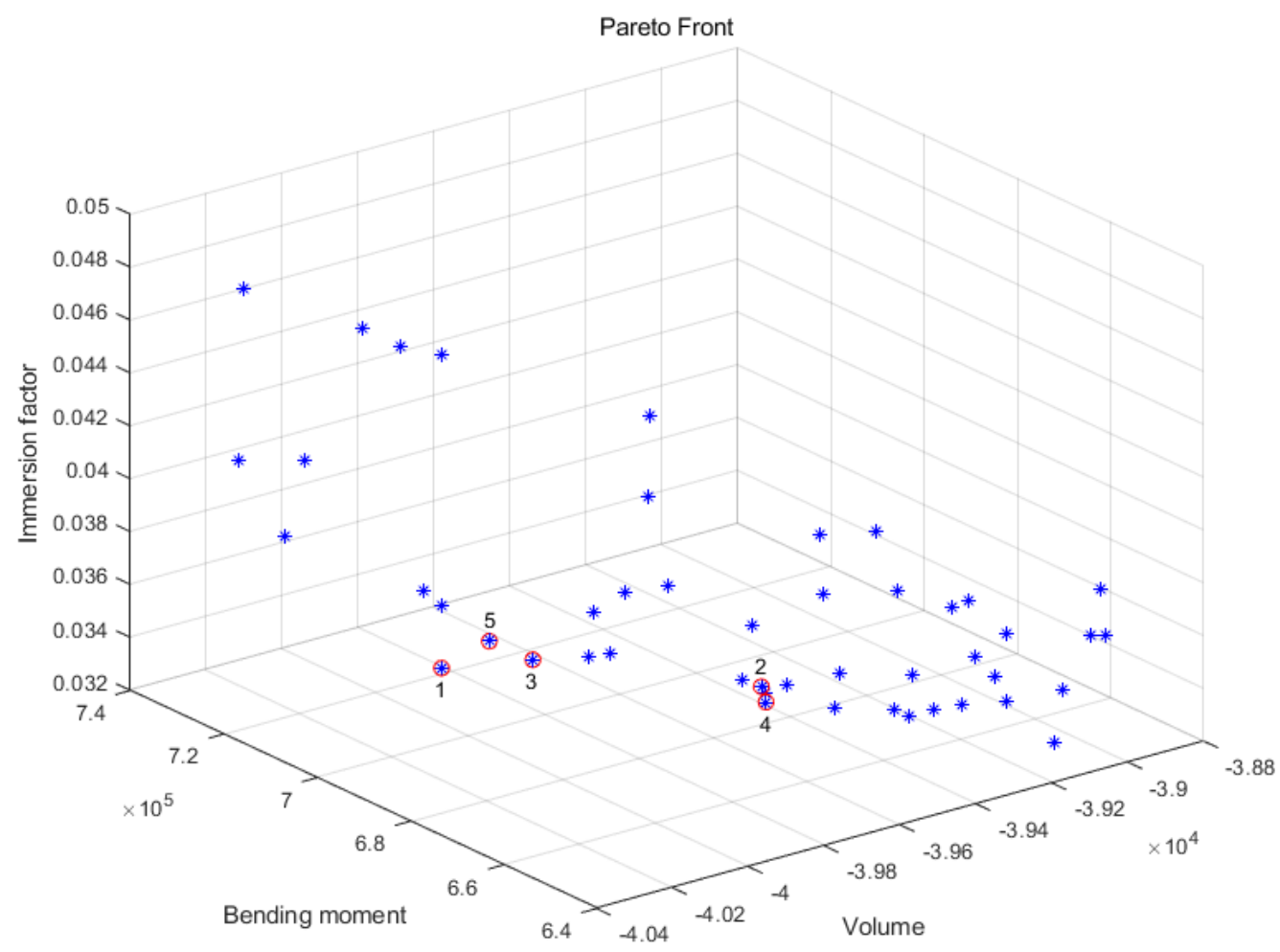

Figure 10. N600T100 Pareto solution set

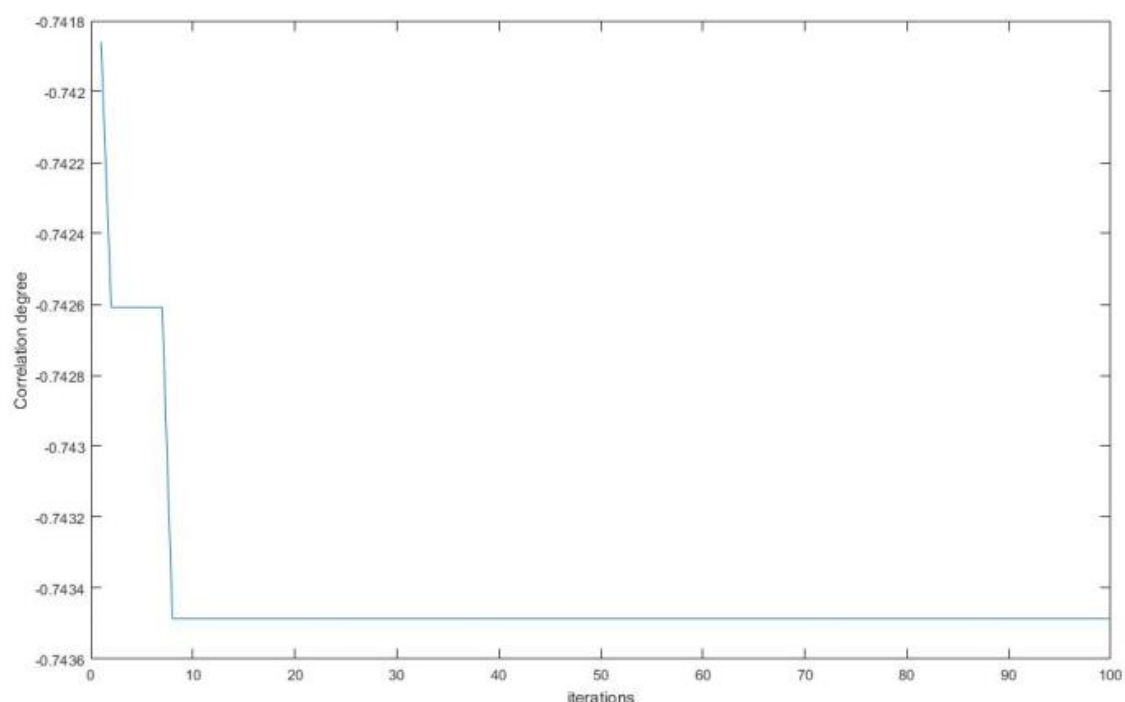

Figure 11. Grey relation degree calculation figure

Note: For the convenience of calculation, the relevance is taken as a negative value. The smaller the value, the greater the degree of association 


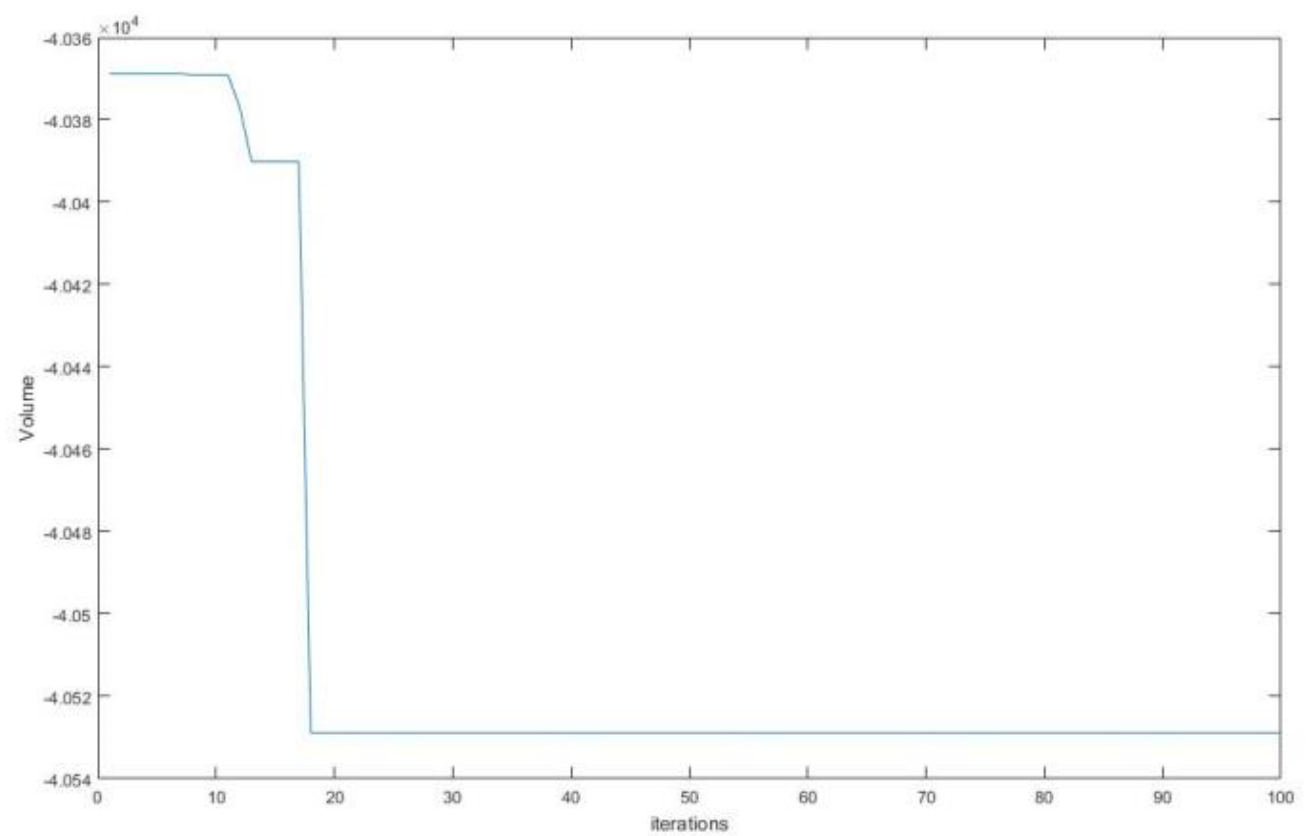

Figure 12. Calculated curves of volume

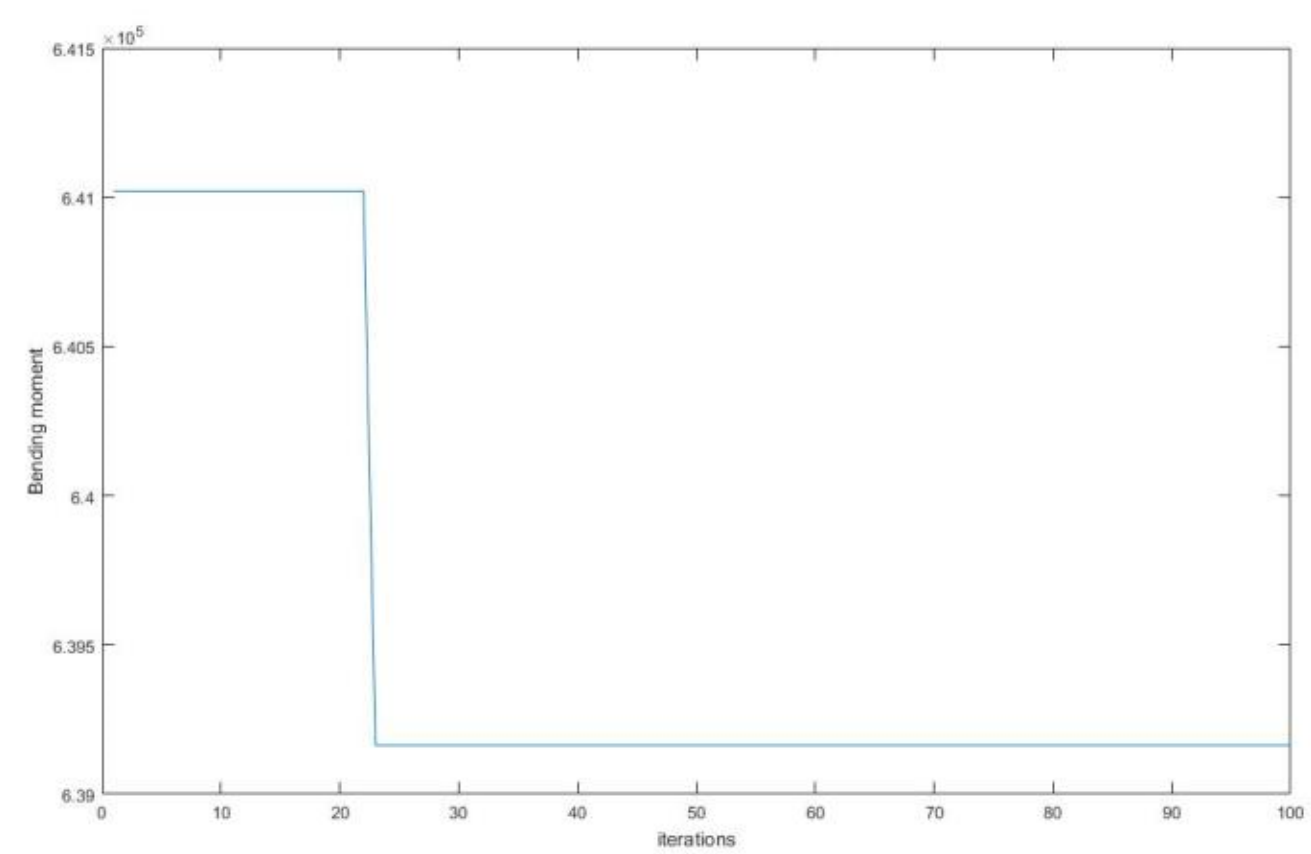

Figure 13. Calculated curves of bending moment 


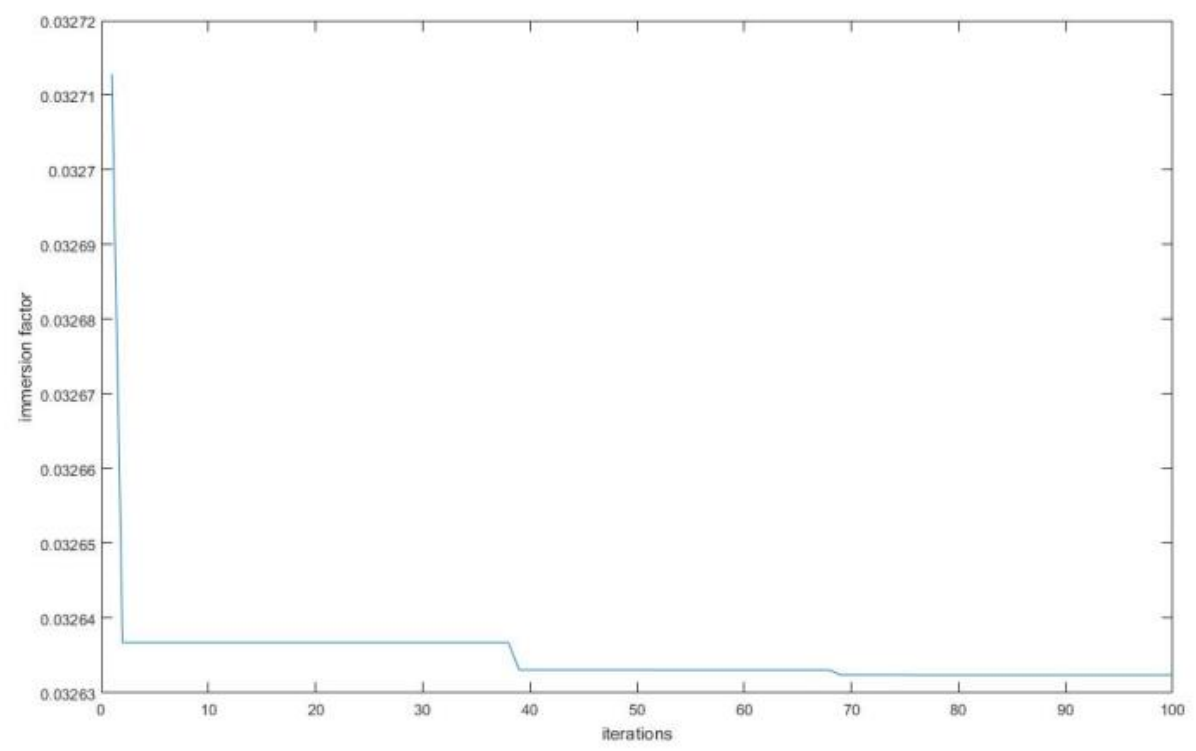

Figure 14. Calculated curves of immersion factor
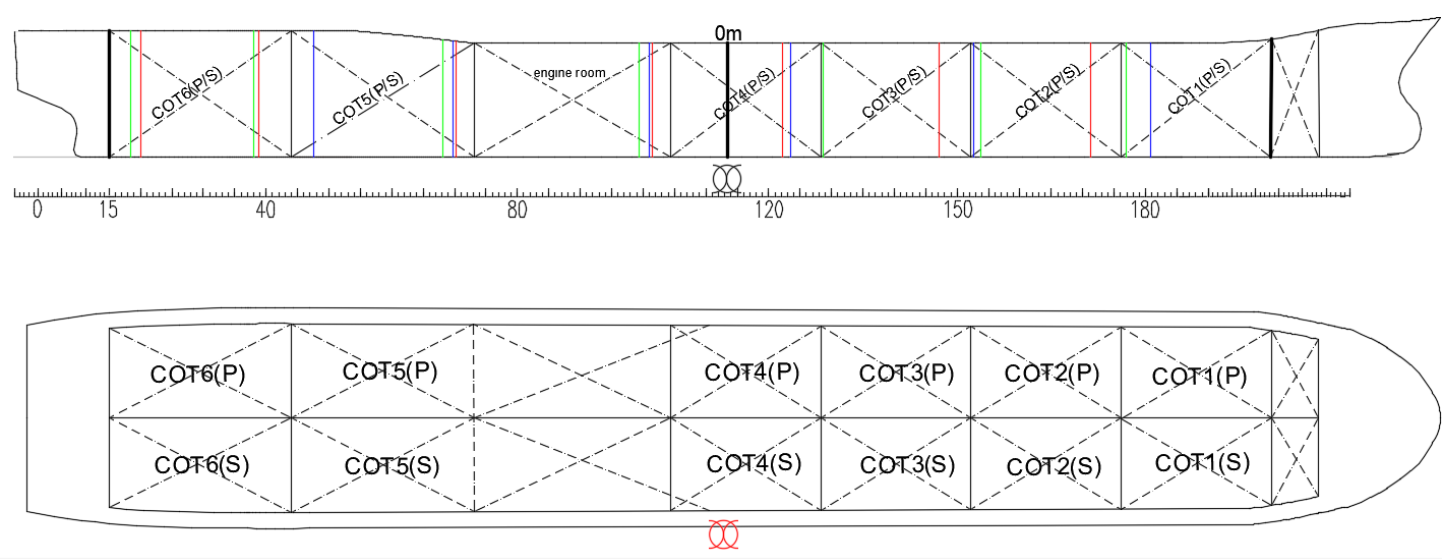

Figure 15. Schematic diagram of single objective optimization subdivision

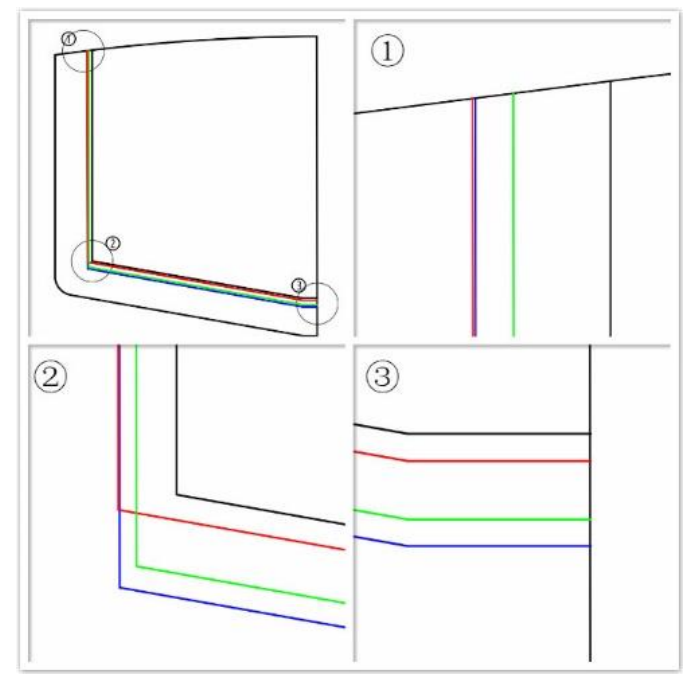

Figure 16. Transverse subdivision scheme and detail diagram 

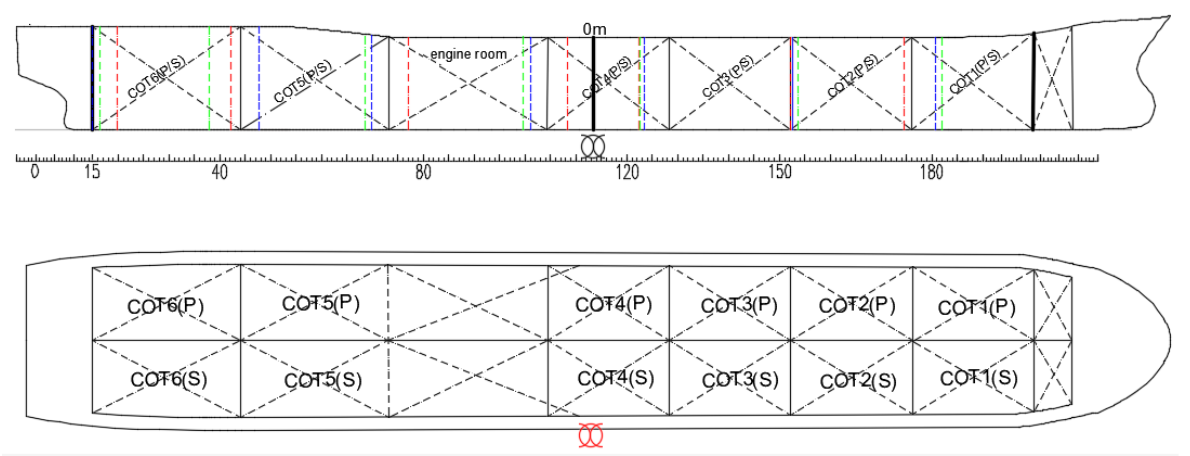

Figure 17. Schematic diagram of multi-objective optimization subdivision

Table 1

Unmanned ship main scale

\begin{tabular}{cccc} 
Length overall & $181 \mathrm{~m}$ & Length between perpendiculars & $173 \mathrm{~m}$ \\
Breadth & $28 \mathrm{~m}$ & Depth & $15 \mathrm{~m}$ \\
Draught design & $11 \mathrm{~m}$ & Displacement & $30000 \mathrm{~T}$ \\
Speed & $14 \mathrm{kn}$ & Bottom dip angle & $10^{\circ}$ \\
Camber height & $1 \mathrm{~m}$ & & \\
\hline
\end{tabular}

\section{Table 2}

Permitted values of performance indicators

\begin{tabular}{lc}
\hline Hull performance & The permissible values $/ \mathrm{m}$ \\
\hline The initial stability height after free surface modification $G M_{\text {perm }}$ & 0.15 \\
Average draught in midship & 5.46 \\
Trim & 2.595 \\
Draught at the perpendiculars of the stern of a ship submerged with & 5.980 \\
propellers & \\
\hline
\end{tabular}

Table 3

Top five cabin subdivision schemes

\begin{tabular}{ccccccccc}
\hline No. & X1 & X2 & X3 & X4 & X5 & X6 & X7 & X8 \\
\hline 1 & -77.54 & -60.39 & -35.99 & -10.99 & 7.34 & 32.16 & 54.86 & 69.25 \\
2 & -76.04 & -59.65 & -37.02 & -12.02 & 7.44 & 33.50 & 54.01 & 69.25 \\
3 & -77.34 & -60.18 & -34.94 & -9.94 & 7.51 & 33.48 & 54.84 & 69.25 \\
4 & -76.09 & -59.10 & -36.74 & -11.74 & 7.60 & 30.88 & 54.09 & 69.25 \\
5 & -77.41 & -59.90 & -35.67 & -10.67 & 7.97 & 32.52 & 55.02 & 69.25 \\
\hline
\end{tabular}


Table 4

Top five objective function values

\begin{tabular}{ccccc}
\hline No. & C ( volume ) & $\mathrm{BM}$ ( bending moment ) $\mathrm{P}($ immersion factor $)$ & $\begin{array}{c}\text { distance from } \\
\text { the origin }\end{array}$ \\
\hline 1 & 40104.06 & 697342.17 & 0.035 & 0.6159 \\
2 & 39592.80 & 670388.84 & 0.035 & 0.6192 \\
3 & 39915.60 & 693119.12 & 0.035 & 0.6275 \\
4 & 39561.88 & 671884.39 & 0.034 & 0.6366 \\
5 & 39976.40 & 697498.13 & 0.036 & 0.6566 \\
\hline
\end{tabular}


Table 5

Top five subdivision schemes

\begin{tabular}{ccccccccc}
\hline No. & X1 & X2 & X3 & X4 & X5 & X6 & X7 & X8 \\
\hline 1 & -74.79 & -57.06 & -29.07 & -4.07 & 7.18 & 30.92 & 48.81 & 69.25 \\
2 & -74.83 & -53.22 & -28.54 & -3.54 & 7.04 & 32.52 & 49.80 & 69.25 \\
3 & -75.05 & -54.90 & -29.88 & -4.88 & 7.40 & 27.30 & 51.85 & 69.25 \\
4 & -74.72 & -53.02 & -35.65 & -10.65 & 9.20 & 31.95 & 49.09 & 69.25 \\
5 & -76.02 & -57.13 & -33.22 & -8.22 & 7.38 & 26.50 & 49.38 & 69.25 \\
\hline
\end{tabular}

\section{Table 6}

Top five objective function values

\begin{tabular}{ccccc} 
No. & C ( volume ) & BM ( bending moment ) & P ( immersion factor ) & G ( Grey correlation ) \\
\hline 1 & 39175.35 & 643854.63 & 0.096 & 0.7434 \\
2 & 39060.02 & 646328.55 & 0.093 & 0.7426 \\
3 & 39218.87 & 652714.13 & 0.109 & 0.7418 \\
4 & 38994.56 & 657152.77 & 0.094 & 0.7401 \\
5 & 39327.86 & 667800.24 & 0.100 & 0.7387 \\
\hline
\end{tabular}

Table 7

Top five volumes

\begin{tabular}{cccccccccc}
\hline No. & X1 & X2 & X3 & X4 & X5 & X6 & X7 & X8 & C ( volume ) \\
\hline 1 & -78.61 & -52.65 & -34.90 & -9.90 & 8.05 & 31.40 & 53.86 & 69.25 & 40528.84 \\
2 & -78.61 & -54.02 & -35.69 & -10.69 & 9.31 & 29.09 & 55.16 & 69.25 & 40420.31 \\
3 & -78.44 & -50.92 & -31.91 & -6.91 & 16.95 & 29.62 & 54.08 & 69.25 & 40408.19 \\
4 & -78.53 & -50.48 & -31.52 & -6.52 & 14.80 & 27.56 & 54.52 & 69.25 & 40407.44 \\
5 & -78.48 & -52.23 & -30.57 & -5.57 & 13.99 & 28.82 & 54.06 & 69.25 & 40403.54 \\
\hline
\end{tabular}

Table 8

Top five bending moment

BM ( bending

\begin{tabular}{cccccccccc} 
No. & X1 & X2 & X3 & X4 & X5 & X6 & X7 & X8 & \\
& \multicolumn{1}{c}{} & & & & & & & moment ) \\
\hline 1 & -74.74 & -59.65 & -34.59 & -9.59 & 6.96 & 26.91 & 46.21 & 69.25 & 639163.73 \\
2 & -74.67 & -56.46 & -28.25 & -3.25 & 7.13 & 29.93 & 45.78 & 69.25 & 640484.88 \\
\hline
\end{tabular}




\begin{tabular}{llllllllll}
\hline 3 & -74.79 & -59.50 & -28.02 & -3.02 & 7.03 & 33.85 & 48.51 & 69.25 & 641021.05 \\
4 & -74.73 & -51.65 & -32.32 & -7.32 & 7.03 & 32.49 & 45.28 & 69.25 & 641748.78 \\
5 & -74.85 & -59.93 & -28.05 & -3.05 & 6.99 & 29.97 & 49.31 & 69.25 & 641752.10 \\
\hline
\end{tabular}


Table 9

Top five immersion factor

\begin{tabular}{cccccccccc}
\hline & & & & & & & & & P (immersion \\
No. & $\mathrm{X} 1$ & $\mathrm{X} 2$ & $\mathrm{X} 3$ & $\mathrm{X} 4$ & $\mathrm{X} 5$ & $\mathrm{X} 6$ & $\mathrm{X} 7$ & $\mathrm{X} 8$ & \\
& & & & & & & & & factor $)$ \\
\hline 1 & -76.05 & -60.32 & -36.27 & -11.27 & 12.18 & 32.27 & 50.77 & 69.25 & 0.032632 \\
2 & -74.68 & -58.91 & -35.71 & -10.71 & 12.29 & 33.99 & 52.80 & 69.25 & 0.032632 \\
3 & -74.92 & -58.49 & -35.73 & -10.73 & 9.81 & 31.68 & 52.03 & 69.25 & 0.032633 \\
4 & -74.70 & -59.10 & -35.22 & -10.22 & 10.46 & 29.46 & 50.20 & 69.25 & 0.032633 \\
5 & -74.78 & -58.96 & -36.14 & -11.14 & 9.41 & 31.61 & 48.77 & 69.25 & 0.032635 \\
\hline
\end{tabular}

